\title{
Equity and Justice in Developmental Science: Discrimination, Social Exclusion, and Intergroup Attitudes
}

\author{
Melanie Killen \\ University of Maryland \\ Adam Rutland \\ Goldsmiths, University of London \\ Tiffany Yip \\ Fordham University
}

May 31, 2016

Citation:

Killen, M., Rutland, A., \& Yip, T. (in press). Equity and justice in developmental science:

Discrimination, social exclusion, and intergroup attitudes. Child Development.

Contact information for corresponding author:

Melanie Killen, Department of Human Development and Quantitative Methodology, University of Maryland, 3942 Campus Drive, Suite 3304, College Park, MD, 20742, USA.

Email: mkillen@umd.edu. Email for Adam Rutland: a.rutland@gold.ac.uk; Tiffany Yip: tyip@fordham.edu 


\begin{abstract}
In this article we assert that: (1) the topics of equity and justice reflect important areas of developmental science theory and research which have not yet been recognized as central areas of research in child development and developmental science; (2) that a concern for social inequalities serves as a common thread binding equity and justice research across different areas in developmental science; and (3) that equity and justice research can inform policies and practices that are designed to improve the lives of stigmatized groups, reduce prejudice and bias, and create programs to rectify social inequalities. For this special section of Child Development, we provide the context for this research and highlight the articles in this special section to demonstrate cutting edge research in developmental science regarding equity and justice. We review current research and make recommendations for new directions for research.
\end{abstract}

Key words: discrimination, social exclusion, intergroup attitudes, equity, justice 
Equity and Justice in Developmental Science: Discrimination, Social Exclusion, and Intergroup Attitudes

Equity and justice are central constructs for how individuals live their lives. The fair and equitable treatment of individuals has been a core value of humanity throughout history, one that has evolutionary roots in the prosocial orientations of non-human primates and other animals, and that has manifested in one form or another in most cultures on earth. Without equity and justice individuals cease to function effectively as group or collective, refrain from cooperative and reciprocal modes of interaction, and ultimately succumb to violence, prejudice, and destructive ends. How do humans develop the ability to treat others with fairness, equity, and equality? More specifically, what is the developmental story for how children develop prescriptive norms of how to treat others, rectify social inequalities, and understand the complexities of balancing fairness with concerns about belonging to social groups, social hierarchies, and social status?

Children's and adolescents' experiences of discrimination, social exclusion, and prejudice impact their trajectories for healthy development and for the ultimate goal of creating a just and civil society. Developing an understanding of how humans come to construct a working theory of equity and justice, and associated behaviors exhibiting this theory, will inform interventions and policies to combat current social and moral inequalities. These are complex issues, but they are fundamental for understanding the human condition, and the factors that promote or hinder social and moral capacities regarding equity and justice.

Social science focus. Despite our view that these issues are central for developmental science, it is only recently that they have been viewed as essential for empirical inquiry in psychology, and more specifically, for child development. In contrast, equity and justice have been long been considered central areas of scholarship, inquiry, and application in the fields of sociology, political science, and philosophy. Sociology and political science have had a long 
history of studying human social behavior and society with a focus on social class, social mobility, and social structure (Durkheim, 1893), and a more recent focus on the mechanisms that underlie social inequality, such as social status based differences (Ridgeway, 2013).

Philosophical writings have formed the basis of theories of justice and fairness (Rawls, 1971), and within the past several decades philosophers have explicitly discussed the constructs of social injustice (Appiah, 2005; Nussbaum, 1999; Sen, 2009), and what is necessary for defining a theory of social equality (Anderson, 1999; Fourie, Schuppert, \& Wallimann-Helmer, 2015; Scheffler, 2015). Interestingly, recent philosophical writings have made comparisons between distributive justice and relational equality, pointing out that theories of distributive justice do not fully allow for the goals of relational equality, or the creation of a "society of equals" (Scheffler, 2015). Societies are inherently hierarchical, and these hierarchies create social stratifications that impede the goals of justice and fairness. These hierarchies do not emerge fully realized in adulthood but have their roots in childhood, in the world of peer interactions as well as adult-child interactions.

Developmental science focus. Developmental science first began investigating issues of equity and justice by analyzing how the existing social stratifications in society create inequalities that have long-term detrimental effects on children's development (see Garcia-Coll et al., 1996; Spencer \& McLoyd, 1990). These life circumstances often translate into social processes of exclusion mediated by intergroup attitudes and lead to discrimination and lack of access to resources. The initial empirical undertakings led to a corpus of data on the long term negative consequences of social stratifications as we describe below (Duncan, Magnuson, \& Votruba-drzal, 2012; Fisher, Wallace, \& Fenton, 2000; Frankenberg \& Orfield, 2007; Marks, Ejesi, McCullough, \& Garcia Coll, 2015; Weiland \& Yoshikawa, 2012). Yet, as put forward by social psychologists (Steele, 1997) and developmental psychologists (Verkuyten, 2011), changing the laws regarding income inequalities, stratifications, and civil rights is only the first step towards equality and justice. What is now necessary is to address how to change 
psychological attitudes, beliefs, and judgments. Until we can change psychological attitudes, the full enactment of laws will be hindered and the laws on their own cannot fully create the desired goal of equity and justice.

The process of changing attitudes has to begin in childhood, as social hierarchies, biases, and stereotypic expectations emerge early. By adulthood, such attitudes are deeply entrenched and difficult to change. This special section of Child Development highlights current cutting-edge research regarding discrimination, social exclusion, and intergroup attitudes in childhood $^{1}$. These three topics were identified by members of the Society for Research in Child Development's Equity and Justice committee as central and current concerns related to equity and justice in developmental science. In this paper, and as members of the Equity and Justice committee, as well as guest editors of this special section of Child Development, we discuss these three topics in developmental science (what we know and what we do not know), the issues in the field, and the empirical findings. We highlight the 11 current papers that were included in the special section as examples of cutting edge research in developmental science, and provide the context for this work in the field of developmental science.

Promoting a society of equals for both how children are treated and socialized, as well as how children develop concepts about others, is a developmental science goal. Developmental science can and should be conducting research that informs strategies and policies to promote the healthy well-being for all children and to investigate the factors that perpetuate, as well as rectify, inequalities. Further, we view this goal as necessary and relevant for all areas of developmental science, including neuroscience, social cognitive development, emotion and affect, motivation, and cognitive development.

The gap. Despite the existence of selected significant and robust lines of developmental science research that address issues of equity and justice for children, current sub-fields remain

\footnotetext{
${ }^{1}$ For the background, history, and rationale for this Special Section of Child Development, please see the online materials accompanying this article.
} 
isolated bodies of research that have not yet coalesced into a larger focus on equity and justice within the field. Research on equity and justice is urgently needed given the long-term negative consequences that result from these phenomena throughout the life-span. Research on societal factors and policy mandates has demonstrated that the absence of equitable and just treatment in childhood contributes to a lack of long-term healthy child development, and in fact, serves as a significant risk factor for negative societal- as well as individual-level outcomes (Duncan et al., 2012; Weiland \& Yoshikawa, 2012). Viewing children as a vulnerable population, this research has documented the long-term negative consequences of being the recipient of inequitable treatment such as being raised in poverty, of experiencing discrimination as a result of one's ethnicity, or living in a community that experiences prejudicial treatment.

Yet, as mentioned, status hierarchies exist in society, including in children's social worlds, and to this end, children are both victims and perpetuators, desiring to rectify inequalities as well as maintain the status quo. Investigations of children's peer worlds reveal social inequalities, existing along with the hierarchies that exist in their larger community and cultural worlds. This means that inequity and injustice begins very early in development. Waiting to address these problems in adulthood, when inequality has already resulted in health and adjustment disparities, is too late. Thus, research should be focused not only at the exogenous level in terms of how children are treated by the external world, but also at the endogenous one, focusing on how children interpret their own experiences and the factors that enable inequitable and unjust behavior and attitudes towards others to percolate up through development. Given the importance of childhood experiences for later lifespan development, developmental science research should identify the factors that promote a society of equals from the beginning of development.

Our goal. Thus, a developmental science perspective is necessary, timely, and relevant for shedding light on equity and justice, fundamentally important aspects of human development. The origins and development of equity and justice from infancy to adulthood 
requires identifying the social, biological, cognitive, emotional, and clinical dimensions of what it means to treat others equitably with mutual respect. In this article, we make three assertions.

First, the topics of equity and justice reflect important areas of developmental science theory and research which have not yet been recognized as central areas of research in child development and developmental science. We would like to call attention to these research areas given the centrality of equity and justice in human development. As mentioned, theorists have argued that the current challenge for researchers studying equity and justice issues is to determine how to change psychological attitudes that reflect stereotypic and prejudicial expectations given that for many countries in the world, but not all, there are laws in place to protect individuals from unequal and unfair treatment.

At the global level, the U.N. Universal Declaration of Human Rights (UDHR), established in 1948, reflects these sentiments as identified in Article 1 that "all human beings are born free and equal in dignity and rights. They are endowed with reason and conscience and should act towards one another in a spirit of brotherhood." The U.N. Convention on the Rights of the Child, ratified in 1989, articulates the necessity for children to live free from discrimination and unequal treatment. Country-specific policies are wide-ranging and include many of the tenants reflected in the global mandates. Nonetheless, violations of laws persist and people still hold beliefs which cause them to find ways to avoid rectifying social inequalities. Thus, much work remains to ensure not only that the laws and expectations are enforced and carried out, but also to determine how best to change psychological attitudes and behavior, which often develop early in childhood and help perpetuate social inequalities.

Changing attitudes requires knowing what attitudes exist and the factors that promote change. For improving children's lives this requires changing attitudes held by adults (parents, teachers, community leaders) as well as those held by children themselves. Developmental psychologists studying this topic have argued that the time for change and intervention is in 
childhood, when negative attitudes that perpetuate social inequalities are labile and only just emerging (Killen, Rutland, \& Ruck, 2011; Marks, et al., 2015; Yip, Douglass, \& Sellers, 2014) Understanding the role of group identity, group norms, and children's own beliefs, judgments, and attitudes are essential for changing psychological attitudes that perpetuate negative inter-individual and inter-group treatment. As well, the messages that parents and teachers convey to children about inclusion or exclusion are powerful forces that need to be fully examined to promote positive social relationships and attitudes in childhood (Bigler, Brown, \& Markell, 2001; Brown, Bigler, \& Chu, 2010). As much as adults often hold biases, parents can also be an important buffer to help children resist the negative outcomes of experiences of discrimination and exclusion (Rivas-Drake, Hughes, \& Way, 2009).

Attitudes about inequality include both explicit and implicit judgments. Until recently it was expected that implicit attitudes were particularly impervious to change. Yet, it has been shown that social contexts and individual factors significantly contribute to the degree to which implicit attitudes are revealed in both adulthood and childhood (Baron, 2015; Lai et al., 2014) In addition, new findings using biological markers provide evidence for the types of social relationships, such as intergroup contact, that can facilitate change (Page-Gould, MendozaDenton, \& Tropp, 2008) These research examples underscore the potential power of applying equity and justice approaches to development science to alter the development of stereotypic and discriminatory attitudes towards marginalized groups (García Coll et al., 1996). Moreover, a multilevel approach is needed, one which cuts across broader economic policy to address discrimination, social exclusion, and intergroup attitudes on the individual and group level.

Thus, our second assertion is that a concern for social inequalities serves as a common thread binding equity and justice research across different areas in developmental science. Specifically, this commonality is apparent in research designed to address social inequalities in children's lives as well as research that reveals children's roles as active agents for perpetuating or rectifying social inequalities in different social relational contexts. We define social 
inequalities as the unfair and unjust treatment of other individuals, often based on group membership (gender, race, ethnicity, religion, sexual orientation), and often directed at those individuals who are members of vulnerable or stigmatized populations. Social inequality occurs when individuals are denied access to resources and opportunities, and/or are excluded from opportunities and social groups solely on the basis of group membership status. An important movement in this field is to examine the beliefs, attitudes, and behaviors of both excluders and the excluded. This means that those who are the recipients of unfair treatment (ethnic minority children, females, marginalized groups) need to be participants in research as much as those who are the perpetuators of negative attitudes and behaviors. The dynamic of how individuals experience and interpret social relationships and interactions requires close scrutiny. The denial of access to resources and social exclusion result in disparities that negatively affect healthy well-being and optimal development.

Thirdly, we assert that equity and justice research can inform policies and practices that are designed to improve the lives of stigmatized groups, reduce prejudice and bias, and create programs to rectify social inequalities. This expectation is one shared by federal agencies that fund basic research in which a detailed accounting of the broader impact or translational products is required and is fundamental to the successful review of proposals. The connection between basic research and policy is essential for developmental science research given that so much is at stake in providing a strong healthy beginning for a life-span of productivity and contribution to the large society and community.

Drawing upon these three assertions, in the remainder of this article we illustrate the first assertion by highlighting the current studies included in this special section along with existing developmental science research concerned with the central issues of equity and justice in childhood. Our selection of research is designed to illustrate our second assertion, and we will also identify how each of these fields of research all address social inequalities in children's lives and children's active roles in supporting or challenging social inequalities. Next, related to 
our third assentation, we underscore the relevance of these fields of research in informing policies and practices that challenge social inequalities and improve the lives of stigmatized groups. Finally, we conclude by returning to our first assertion with recommendations for, and benefits of, making equity and justice a central focus in developmental science.

\section{Existing research on Equity and Justice}

To highlight the current research papers for this special section, we have grouped the studies along these categories, reflective of the three areas for the special section: discrimination, social exclusion, and intergroup attitudes. Besides a focus on equity and justice, the highlighted research shares in common explicit attention to the social contexts that shape development. Importantly, the research highlighted here ranges from micro to macro--level contexts. At the micro-level, we review research on proximal levels of context; we focus on youth's experiences of discrimination, with a particular focus on unfair treatment due to racial/ethnic group membership. Within the section on discrimination, we offer an even more granular multilevel approach reviewing research on how discrimination gets "under the skin" to influence physiological outcomes in peer, school, and neighborhood contexts. In the section on social exclusion we acknowledge that this area spans multiple levels by focusing on the neuroscience of social exclusion to social cognition about interpersonal exchanges, as well as the influence of group and societal norms on exclusion decisions. In the section on intergroup attitudes we discuss the role of group identity on the formation of in-group and out-group attitudes and its bearing on the denial of fair and equal treatment of others. Finally, we bring back the focus of the topic of equity and justice to the impact of national economic policies related to prenatal care, early child education, maternal health, and distribution of resources, which has implications for policies and interventions.

Children's experiences of discrimination. Research on children's experiences of discrimination has shown a robust association between these experiences and compromised developmental outcomes (Pascoe \& Smart Richman, 2009). These resultant poor 
psychological, academic, behavioral and physical health outcomes in childhood help to perpetuate social inequalities and sustain societies that are not founded upon on the principles of equity and justice. As befits a developmental science concerned with equity and justice there has been a specific focus on uncovering how and why discrimination is associated with poor adjustment, and how these associations change or persist over time. Because discrimination has been linked to a host of negative outcomes, inquiries into the sources and consequences of discrimination have naturally resulted in investigations spanning multiple levels of developmental contexts, from proximal biological contexts to more distal neighborhood ones (Marks, et al., 2015).

While discrimination and mistreatment can arise due to a variety of reasons related to marginalized social group memberships, the bulk of recent research in social science broadly, and developmental science in particular, has focused on discrimination due to membership in a racial/ethnic group. This testifies to the fact that social inequality within most societies has much of its origins in racial/ethnic differences and a long history of discrimination based upon race or ethnicity. A recent meta-analysis found that $65 \%$ of articles on discrimination focus on racial or ethnic treatment, with the next most common focus on gender discrimination representing $17 \%$ of studies (Pascoe \& Richman, 2009). This supports the scientific community's interest in how mistreatment due to one's racial/ethnic group membership impacts child and youth development and outcomes.

A developmental science, however, focused upon equity and justice for all groups that experience inequity requires more research on other forms of discrimination, including gender discrimination, which represents both prejudice based on gender as well as differential treatment due to sexual orientation (Horn \& Sinno, 2014). Importantly, current investigations are moving towards a more systematic investigation across multiple levels of influence. This includes investigations starting at the most proximal level such as basic physiological 
processes, to interpersonal interactions, to more institutionally based discrimination evidenced in schools and neighborhoods.

How discrimination impacts developmental outcomes. At the most proximal level, research on discrimination is increasingly focused on inquiries related to how discrimination gets "under the skin" (McEwen, 2012) to influence various outcomes. Theories emphasizing how social experiences of discrimination are embodied in physical health outcomes are increasingly gaining traction. For example, the ecosocial model directly links interpersonal and institutional discrimination to physical health outcomes and disparities (Krieger, 2012). Specifically, stress from discrimination is biologically embodied and manifested in compromised health. Similarly, psychophysiological approaches provide pathways linking stress from discrimination to immediate and online indicators of health such as heart rate, blood pressure and cortisol (Harrell, Hall, \& Taliaferro, 2003). Stress from discrimination is also associated with increased physiological arousal leading to the examination of biomarkers such as cortisol, blood pressure, telomere length, $\mathrm{fMRI}$ and sleep to indicate the impact of discrimination related stress on physiological functioning. Informed by such theories, recent research has ventured into investigating biomarkers of race-related stress and discrimination employing cutting-edge physiological indicators. Most recently, research has shown that infants of mothers who experience discrimination during the last trimester of pregnancy also show elevated cortisol responses compared to mothers who do not report experiencing racial discrimination in pregnancy (Thayer \& Kuzawa, 2015); suggesting that the effects of discrimination can be transmitted intergenerationally via physiological pathways. This body of results demonstrates that inequity and injustice via discrimination leaves a physical and psychological mark upon individual child and helps to sustain deep-rooted social inequalities in many societies.

Adding to psychophysiological approaches, social scientists and psychologists are also considering how variations in ethnic/racial identity and attitudes may protect individuals who experience discrimination from some negative physiological responses. For example, the impact 
of discriminatory experiences on levels of ethnic/racial identity is demonstrated by exploring cardiovascular response (Neblett \& Carter, 2012) and cellular aging, as indicated by telomere length (Chae et al., 2014). While these studies exemplify the research on the physiological impact of discrimination on biomarkers, there is little to no such research conducted with youth. However, one area that has received some attention is the relationship between discrimination stress and a fundamental biological marker of adolescent health - sleep. Recently, researchers have begun to explore the joint effects of sleep and discrimination on adolescent outcomes with data suggesting that adolescents reporting high levels of discrimination and low levels of sleep quality reporting the worst socioemotional (Yip, 2015) and academic (Dunbar, Mirpuri \& Yip, 2016) outcomes over time, especially compared to adolescents reporting low levels of discrimination and high sleep quality.

Discrimination in schools. Moving towards more distal contexts, there is also growing research exploring the impact of discrimination on individual-level outcomes such as academic achievement and well-being. This research shows that discrimination not only has negative physiological consequences but also contributes to sustaining and creating social inequalities in children's performance at school and their psychological well-being. A developmental science of equity and justice helps us understand the origins of these inequalities in the discriminatory experiences of children and adolescents

For example, discrimination in education and peer contexts has been found to be associated with lower self-esteem (Fisher, et al., 2000), higher depressive symptoms (Greene, Way, \& Pahl, 2006), and decreased academic outcomes (Benner \& Graham, 2007). A focus on interpersonal interactions between individuals has led to investigations of perpetrator characteristics. For example, Hughes, Del Toro, Harding, Way, and Rarick (in press) distinguish between discrimination perpetrated by a non-school adult, overt discrimination perpetrated by peers, and covert discrimination perpetrated by peers, thereby providing a more nuanced picture of both the source and type of discrimination. Indeed, the sources and forms of 
discrimination are differentially experienced across racial/ethnic groups and have differential effects on both concurrent and longitudinal outcomes. For example, compared to Black, Latino and White youth, Chinese youth reported more overt peer discrimination in the $6^{\text {th }}$ grade, and while other youth reported declines in discrimination in middle and high school, Chinese youth report more modest declines. When considering covert peer discrimination however, another pattern emerged. While Black and Chinese adolescents reported the highest levels in the $6^{\text {th }}$ grade, Black adolescents reported a steeper increase over time. Importantly, all three forms and sources of discrimination in the $6^{\text {th }}$ grade were associated with compromised academic, wellbeing and behavioral outcomes two years later. These findings indicated that discrimination, no matter who perpetrates it and what form it takes, is longitudinally connected to the development of social inequalities which sustain inequity and injustice.

In a recent study investigating discrimination outside of the U.S. context, Baysu, Celest, Brown, Verscheuren, and Phalet (in press) also finds discrimination, together with negative stereotypes and perceptions of unequal treatment, within the school context predicting more negative cognitive task performance among Turkish and Moroccan minority youth in Belgium. Importantly, this effect was mediated through task disengagement. From a developmental perspective, it was important to note that in a sample spanning middle to late adolescence, the impact of discrimination and perceptions of equal treatment compromised task disengagement the most for late-adolescent youth reporting high levels of unequal treatment and discrimination. Similar patterns were not observed for the younger students.

Taken together the studies by Hughes et al., and Baysu et al. both, though in different contexts, underscore the importance of school as a setting in which discrimination creates social inequalities; more importantly, the studies focus on how social interactions with peers and adults in schools are central to the process by which equity and justice is hindered in children's everyday lives. While the Hughes et al (in press) study focused on the consequences of sources and types of discrimination on academic and socioemotional development longitudinally, the 
Baysu et al (in press) study focused on individual-level mediating mechanisms that link discriminatory treatment with youth outcomes.

Discrimination in neighborhoods. In addition to schools, there is increasing recognition of the roles that neighborhoods have on experiences of discrimination and the perpetuation of social inequalities in developmental outcomes. In fact, neighborhoods may represent the most macro-level context that scholars have linked to discrimination experiences. Often, however, such research explores the interaction of the developing child in these educational and neighborhood contexts. Together, this area of research suggests that schools and neighborhoods indeed have powerful effects on discrimination and associated developmental outcomes. For example, Hughes et al (in press) find that youth attending more ethnically diverse middle schools reported less steep increases in peer discrimination over time, underscoring the benefits of diversity. Turning to neighborhood effects, Witherspoon, Seaton, and Rivas-Drake (in press) observed Census-derived indices of neighborhood disadvantage in the $7^{\text {th }}$ grade to be associated with increased expectations of racial discrimination in the $8^{\text {th }}$ grade and in to adulthood. This effect, in turn, was mediated through youths' perceptions of neighborhood conditions. Therefore, objective neighborhood conditions such as percent unemployed, percent female-headed household, and percent families in poverty were associated with more negative youth perceptions of their neighborhoods, which led to subsequent beliefs about the prevalence of racial discrimination.

Future directions for research on children's perceptions of discrimination. Looking forward, research on the topic of discrimination in developmental contexts will benefit from more longitudinal research with large and diverse samples. Both Hughes et al (in press) and Witherspoon et al (in press) benefitted from data spanning middle to high school. Such datasets are rare, yet imperative, as they have the potential to address important developmental questions. For example, Hughes et al (in press) found that discrimination increases across the 
middle school years, yet declines in high school. While descriptive, this type of observation is only possible with large, longitudinal data sets.

Another area worthy of deeper inquiry builds upon recent research seeking to identify how the source and type of discrimination (Benner \& Graham, 2013; Hyunh \& Fuligni, 2010; Marks, et al, 2015) may be differentially associated with the development of inequalities in mental health, academic and social outcomes. For example, future research should not only consider the source and type of discrimination, but also characteristics of the perpetrator. Some research suggests that intragroup discrimination from in-group others may be more detrimental than discrimination from known out-groups with a history of perpetrating discrimination against one's group. The Baysu et al (in press) paper underscores the importance of considering how discriminatory processes are enacted in contexts outside of the United States. While the histories of ethnic minority groups are unique to each country, there are likely certain universal principles of race- and ethnicity-based discrimination that transcend geographical or historical boundaries.

Finally, research on the impact of discrimination broadly and within developmental science has been limited to a focus on singular aspects of identity, primarily race and to a lesser extent gender (Pascoe \& Richman, 2009). Scholars have long recognized that all individuals are members of multiple social groups and that the intersection of these identities impacts discrimination experiences and its impact on development (Chavous et al., 2008, Garcia Coll et al 1996); however, this area of research is still in its infancy. Indeed, recent research finds that African American boys experience more classroom and peer discrimination than African American girls, and that this gender difference is further exacerbated for boys reporting lower family SES (Chavous et al., 2008). Moreover, discrimination in the $8^{\text {th }}$ grade has downstream impact on a broader range of boys' academic outcomes, compared to girls (Chavous, et al., 2008). This evidence suggests that the intersection of multiple identities and their impact on 
discrimination and social inequalities in terms of psychological outcomes is a fruitful and important topic for future research.

It is also notable that, while detrimental effects of discrimination are consistent with meta-analytic conclusions (Pascoe \& Richman, 2009), developmental science research has utilized multiple different indicators of discrimination. Despite these differences between studies, research focused on the experiences of racial/ethnic minority groups in their respective contexts has found similar detrimental effects of unfair treatment. Even experimental research focusing on psychophysiological indicators of discrimination stress asks participants to imagine themselves in a social interaction (e.g., Neblett \& Roberts, 2013). As such, regardless of what level developmental science explores the impact of discrimination, the source of discrimination remains largely at the individual level. However, a multilevel approach affords the opportunity for a more granular investigation of developing youth and their perpetrators embedded within and across specific contexts.

Children's evaluations of intergroup social exclusion. As discussed above, children who are discriminated against and socially excluded from their peers on the basis of group membership, such as gender, race, ethnicity, culture, religion and sexual orientation, are at risk for barriers to healthy development (i.e., they experience social withdrawal, anxiety, depression, and a lack of motivation for successful academic outcomes). Comprised development in childhood due to discrimination and social exclusion helps maintain social inequalities and is counter to the principles of equity and justice. Importantly children are not just discriminated against by parents and teachers who hold implicit and explicit biases, it has been demonstrated that children are also the beholders of attitudes (both implicit and explicit) that lead to negative inter-individual peer interactions, creating intergroup tensions and conflict in school and community contexts (Juvonen, Nishina, \& Graham, 2006; Killen \& Rutland, 2011; Pitula, MurrayClose, Banny, \& Cricfk, 2015; Rutland \& Killen, 2015). 
As demonstrated by Mulvey, Palmer and Abrams (in press), by adolescence, racial bias is displayed in more indirect social group contexts, such as found with race-based humor and adolescent's expectations about peer responses to discrimination. In their study, with age, European-American adolescents judged race-based humor as more acceptable than did younger adolescents, and were less likely to expect peer intervention. Adolescents who rejected this form of humor focused on the harmful consequences to others. As with gender stereotypes, however, adolescents who viewed it as wrong also expected that they would be excluded from groups if they intervened to stop race-based humor from occurring within their own peer groups.

Similar to the transformation of social psychological research on prejudice from a focus on individual psychopathology to group norms, identity, and group dynamics developmental intergroup research on social exclusion has recently focused more directly on how group processes contribute to the emergence of prejudice (intergroup relations) rather than how individual personality traits of children result in rejection from peers (interpersonal relations). The significance of group processes was demonstrated by Brenick and Romano (in press), who found that cultural group identity and group norms are related to evaluations of social exclusion. This study examined how Jewish-American youth evaluated Arab-American inclusion and exclusion in different contexts (peers and family). It showed that perceived group norms were influential on when participants viewed exclusion as legitimate. In the peer context, adolescents who judged that their peers held positive attitudes about an Arab outgroup were less accepting of exclusionary behavior (and the reverse was the case; adolescents who judged peers to hold negative attitudes were more accepting of exclusion). In the home context, perceived peer norms were also a predictor of exclusionary attitudes above and beyond parental norms, indicating that parents are only one source of influence on adolescent exclusionary practices. Overall, this study revealed the ways that group norms are influential on adolescent exclusionary beliefs regarding cultural identity. 
Research on children's judgments, attitudes, and beliefs about social exclusion of peers has revealed that children have an emerging understanding of hierarchies, status, and power that often maintains the status quo of social inequality at the expense of fair and just treatment of others (Killen, Mulvey, \& Hitti, 2013). Children as young as 4 and 5 years of age associate race with wealth status (Newheiser \& Olson, 2012) and, with age, understand connections between poverty and inequality (Mistry, Brown, Chow, \& Collins, 2012). Given that friendship is a powerful foundation for social development, refraining from becoming friends with peers who are perceived to be part of the stigmatized outgroup has negative consequences that warrant focused research to understand the factors that perpetuate this type of psychological attitude. When children hold negative attitudes about peers based on group membership and social status, and these judgments are left unchallenged or, worse, promoted, then these judgments contribute to prejudicial attitudes, unfair treatment of peers and ultimately supporting the maintenance of social inequalities.

Social exclusion based on group membership such as gender, race, ethnicity, nationality, sexual orientation, and religion begins in childhood and continues through adulthood helping to sustain social inequalities. As an example, in early childhood Pauker, $\mathrm{Xu}$, Williams, and Biddle (in press) identified two social cognitive components of racial attitudes which are race salience and racial stereotypes. Race salience is the tendency to categorize others by race, which is also associated with other variables such as status (Bigler \& Liben, 1993). Pauker et al. (in press) identified racial essentialism as the belief that racial group membership is fixed and reflects an underlying essence shared by like individuals. Essentialist thinking plays a role in stereotyping and particularly out-group stereotyping. In Pauker et al.'s (in press) study, children in Hawai'i and Massachusetts, who had different levels of exposure to diverse groups, differed in their level of essentialist thinking about race (which was higher in Massachusetts than Hawai'i), and racial stereotyping increased with age only in Massachusetts, where the sample selected was predominantly European-American with little intergroup contact. 
Gender stereotyping and expectations are also evident in childhood by a recent study conducted by Andrews, Martin, Field, Cook, and Lee (in press). In their study, they demonstrated the basis by which gender expectations form the basis for perpetuating gender segregation as well as gender social exclusion. Left unchallenged these biases transform into classroom expectations regarding academic as well as social abilities and opportunities, so helping maintain from an early age social inequalities within society. Research has shown that children and adolescents view gender exclusion in stereotypic contexts as unfair, but often expect that groups will dislike those who challenge gender norms (Mulvey \& Killen, 2015). Related work by Horn and her colleagues (Horn, 2007) have also shown that social exclusion based on sexual orientation is viewed negatively by most children, but group pressure often inhibits their vocalization of their views in group settings. This recognition of group norms, designed to maintain the status quo and social inequalities, appears to be a major obstacle for children to resist appearing disloyal to the group.

Investigating children's social-cognitive judgments about social exclusion based on group membership has revealed why children view exclusion to be unfair or legitimate. Research has shown that children view exclusion from groups as unfair in straightforward contexts, but when situations become complex or ambiguous, group functioning considerations as well as stereotypes, biases, and prejudicial attitudes are often invoked (Gieling, Thijs, \& Verkuyten, 2010; Hitti \& Killen, 2015; Tenenbaum \& Ruck, 2012; Wray-Lake, Syvertsen, \& Flanagan, 2008). Age-related changes have revealed that young children are less aware of group dynamics than are older children. This lack of knowledge bears on their expectations of how they expect groups to respond to members that are disloyal to the norms of the group. With age, and in ethnically diverse schools, perceptions of equal treatment buffers threat effects for minority adolescents, revealing the importance of promoting equity and equality norms in school contexts (Baysu, et al, in press). 
Recently, research on resource allocation reveals ways in which the perpetuation of social inequalities and bias in childhood which have implications for social exclusion (Elenbaas \& Killen, in press; Schmidt, Svetlova, Johe, \& Tomasello, 2016; Rizzo \& Killen, in press). In one study, African-American and European-American 5 - 10 year olds were asked to divide resources among peer groups that were disadvantaged or advantaged (and for groups that differed by race) and found that children rectified inequalities by giving more resources to the disadvantaged group; while in-group bias was also apparent with younger children, older children focused largely on societal disadvantaged status without revealing an in-group bias (Elenbaas \& Killen, in press). The denial of resources to a disadvantaged or stigmatized group is also one way to sustain social inequalities, which violates moral principles of equity and justice. Most resource allocation studies test how children allocate resources to same-group or same-race targets. With the exception of a handful of studies, little research has investigated how young children take into account the status or group membership of the recipients of resource allocation, or the potential for physical or psychological harm resulting from inequality. This is a fruitful line of research for incorporating social inequalities into the study of moral cognition as well as social exclusion in childhood.

Not only does intergroup social exclusion negatively affect the excluded recipient, it also has negative outcomes for those who exclude others. This is because perpetuating inequality and inequity creates antagonism and tensions in perpetuators' own experiences in intergroup contexts, such as in schools, college, and the workforce, contributing to cycles of interpersonal and intergroup conflict. As one example, physiological measures of stress have shown that European-American White college students who reported very low levels of opportunities for cross-race friendships in high school experience physiological stress when interacting with a college dorm roommate of a different race (Page-Gould, et al., 2008). Short-term interventions to promote cross-race friendships among these college students produced a reduction in the 
physiological levels of stress. The authors aptly titled their article, "why egalitarianism might be good for your health."

Thus, as with our discussion of discrimination research, studies on social exclusion have been conducted at different levels of analysis. Research in social neuroscience, for example, has validated the hurtful experiences of social exclusion. For example, experiences of social exclusion activate brain regions that are also affected by experience of physical harm

(Eisenberger, 2006; Masten et al., 2009) and rejection sensitivity (Berenson et al., 2009). These studies have focused on the recipient of exclusion, and additional research on the neuroscience and physiological consequences of holding stereotypes and biases about others should also be conducted.

At a more macro level, civic engagement opportunities for children and adolescents are designed to promote social inclusion, equity and justice. A meta-analysis on the role of reflection in the effects of community service on adolescent development revealed that community service had a positive effect on academic, personal, social, and civic outcomes, and particularly so when reflection was part of the experience (Van Goethem, Van Hoof, Orobio de Castro, Van Aken, \& Hart, 2014). Extending these findings to social trust and social justice beliefs, Flanagan and her colleagues have demonstrated that different access to societal opportunities (SES) is related to whether adolescents expect that their social status is a function of their personal misfortunes or the societal system that maintains the status quo (2007). Incorporating these measures with those from other areas of developmental science will provide a stronger coherence of the origins of equity and justice from infancy to adolescence.

Future research on social exclusion. New lines of research on children's reasoning about social exclusion and social inequality will provide information regarding how inequities are perpetuated in childhood by children as well as by adults, and the contexts in which children readily challenge such inequalities. Taking an integrative approach, it will be fruitful to examine 
how children's and adolescents' personal experiences of social stratification are related to their judgments about inclusion and exclusion based on these same indices.

For example, when studying ethnic and racial exclusion, it is essential to investigate the perspectives from different ethnic and racial groups, and to determine how (and whether) being a member of a group that is identified as having high or low status is related to experiences about inclusion and exclusion. It is also important to examine the judgments, evaluations, and expectations of different ethnic and racial groups about whether others at the low or high end of the status hierarchy would rectify, perpetuate, or maintain the status quo when given an opportunity to make such decisions. Moreover, intervention research is needed to determine how to change these attitudes. In the next section we describe research on intergroup attitudes.

Children's intergroup attitudes. Children's decisions to discriminate against or socially exclude others from different groups typically originate from their intergroup attitudes and prejudices. Development science research into intergroup bias and prejudice has attempted to understand the emergence of these insidious attitudes in childhood and adolescence, in order to identify key factors that facilitate or hinder prejudice development. These attitudes should be the focus of attention when challenging social inequalities and form a cornerstone of a developmental science that takes equity and justice seriously.

Research in this area dates back to studies in the 1970s and 1980s showing explicit prejudice in middle childhood, especially in relation to racial and ethnic groups (Aboud, 1988; Katz, 1983). Much of this early research identified some of the social-cognitive characteristics that make children vulnerable to showing ingroup bias, such as young children's difficulties in considering multiple social categories and their tendency to fixate on single perceptually salient social categories when evaluating individuals from different groups. Recent research has suggested that children's cognitive categorization skills are less important for the development of biases and prejudice (Nesdale, 2004). Instead, this research has shown that children's developing social cognitive capacities, such as knowledge about groups (e.g., intergroup 
dynamics) and mental state knowledge (e.g., theory of social mind), combined with their environmental influences, determine whether they show prejudice towards stigmatized groups, perpetuate social inequalities and deny equity and justice to others.

Research drawing from developmental social identity theories (Nesdale, 2004; Rutland, Killen \& Abrams, 2010) has shown that the norms of the peer in-group are a significant influence on children's intergroup attitudes. This research has shown that children's motivation to maintain a positive image amongst peers means the norms of the peer group hold a powerful influence (e.g., Nesdale, Maass, Durkin, \& Griffiths, 2005; Rutland et al., 2005). Nesdale, Maass, Kiesner, Durkin and Griffiths (2008), for example, demonstrated how an exclusionary peer in-group norm made children more likely to say they would bully an out-group child. Effects have also been found on intergroup attitudes, with Nesdale and Lawson (2011) showing that both peer and school norms influencing the attitudes of seven- and ten-year-old children. In this study, children were led to believe that the peer in-group had either an inclusionary or exclusionary group norm, and that the school had either an inclusionary school norm, or no school norm. It was found that an inclusive school norm led to more positive out-group attitudes, though this norm did not act to moderate the negative effects of an exclusionary peer group norm on children's intergroup attitudes. Therefore, to tackle discrimination and the social inequalities it engenders we not only have to create inclusive norms within our schools but we need to facilitate the development of inclusive norms amongst and within peer groups.

These findings fit with a significant body of recent research which has shown that, from middle childhood, intergroup attitudes are influenced by self-presentational and normative concerns, with children being responsive to the normative climate (i.e., inclusive or exclusive) and adapting their explicit attitudes (McGuire, Rutland \& Nesdale, 2015; Sierksma, Thijs, \& Verkuyten, 2014). Recent research by Tropp, O’Brien, Gonzalez, Valdenegro, Migacheva \& De Tezanos Pinto (in press) has shown how perceived school and peer norms simultaneously contribute to predicting inter-ethnic attitudes and contact in both the United States and Chile. 
Cross-sectional results from this research showed that, while both school and peer norms seemed influential, peer norms were a more consistent predictor of students' comfort, interest in cross-ethnic friendship, and high quality inter-ethnic contact. However, longitudinal results from this research indicated that school norms - rather than peer norms - were a more consistent predictor of change in students' comfort, interest, and contact quality over time. These findings suggest that peers are a significant source of normative information at any set moment in time, but the predominant norms in children's school environment are especially important role in determining their inter-ethnic attitudes and experiences over time. Here it is clear that peer group norms of exclusion can promote prejudice and discrimination, but an inclusive normative climate in schools can in the long term reduce the intergroup biases that are a key component to the maintenance of social inequalities.

The relationship between peer norms and individual attitudes is a two-way street, however, with children using their intergroup attitudes as a heuristic when making judgments about the norms of their peer group - a process known as self-anchoring. Thijs and Verkuyten, (in press) investigated social influences via a reversed process of social projection whereby children have the tendency to assume that others think, feel and behave similarly to themselves (Robbins \& Krueger, 2005). Thus peer norms do not only influence children's intergroup attitudes, but these evaluations also affect the perception of peer norms. There are important moderators on this social projection effect, with it being stronger amongst ethnic minority status children who showed strong ingroup identification, and lower with children showing more selfuncertainty (i.e., less reliance on the self when making judgments).

These findings are consistent with the research showing that social projection is stronger when there is overlap between self and others, since closeness between an individual's sense of self and their group membership suggests they expect to agree more with ingroup members (Tajfel \& Turner, 1986). These findings indicate that, while peer group norms can be a significant influence on the development of intergroup attitudes, for peers to have a positive 
influence it is important that the information about what peers actually think is unambiguous and clear-cut. Interventions concerned with reducing intergroup biases and, therefore challenging social inequality created through these attitudes, this research suggests should ensure that children actively discuss issues surrounding discrimination and prejudice with their peers so they don't project their own attitudes onto their peer groups.

Developmental science research has also demonstrated that children's intergroup experiences influence the development of their intergroup attitudes. Based upon the 'contact hypothesis', research has shown that intergroup contact (i.e. direct or indirect interaction between individuals from different social groups) promotes positive attitudes towards other social groups (Allport, 1954) and undermines the potential to maintain social inequalities through discrimination. An important aspect about the intergroup contact hypothesis is that certain optimal conditions need to be met for contact to reduce prejudice. Forcing children and families to live together when there is an absence of these conditions -- equal status, common goals, opportunities for cross-group friendship, and a general sanctioning of the goals of integration from the authority and adults in the community -- may result in an increase, not decrease in prejudice. Thus, research has carefully examined whether the optimal conditions of contact are present when intergroup experiences are created (Pettigrew \& Tropp, 2005).

There exists a significant body of research showing that contact between children from different social groups under certain conditions reduces childhood prejudice (e.g. Feddes, Noack, \& Rutland, 2009; Rutland, Cameron, Bennett, \& Ferrell, 2005). There is also evidence that indirect contact, merely being aware of friendships between members of one's own group and another group can also reduce prejudice amongst adolescents (Turner, Voci, \& Hewstone, 2007) and young children (Cameron, Rutland, Brown \& Douch, 2006). This is important since children living in ethnically and culturally homogeneous contexts often have little contact with those from other groups, and this type of vicarious contact could change their attitude enough that they will seek future direct contact and experience less anxiety when interacting with 
outgroup children. Direct contact is more effective that indirect contact in improving the intergroup attitudes of children living in heterogeneous areas, with the effectiveness of indirect contact being most evident in non-diverse settings (Cameron et al., 2011; Feddes et al., 2009). These findings suggest that intergroup contact in various guises, depending on the intergroup context, generates more positive intergroup attitudes so creating more harmonious relations between groups of children and reducing the potential for discrimination that reinforces social inequalities within society.

Recent developmental research has examined the long-term effects on intergroup contact on adolescents' intergroup attitudes by considering social network dynamics as illustrated by Wölfer, Schmid, Hewstone, and van Zalk (in press). Such an approach does not rely on individuals self-reporting contact, and instead focuses on the complexity of social networks as determined by peer nomination, which can be portrayed with social network analysis that structures relationships among network members giving useful insights into relations within and between social groups. The application of social network data allows a more objective measurement of intergroup contact by identifying reciprocally connected network members. A novel aspect of Wolfer et al.'s (in press) study was its wide scope regarding the populations sampled, which included 14-year old children of Turkish, Polish, and Italian background living in Germany; of Turkish, Moroccan, and Indonesian background living in The Netherlands, and of Iraqi, Polish, and Iranian background living in Sweden. Wölfer and colleagues (in press) found intergroup contact amongst adolescents led to the development of positive intergroup attitudes, whereas in early adulthood, it was shown that this relationship reverses in that current attitudes affect the development of contact, while these same attitudes seem unchanged by contact.

This research suggests that intergroup contact is most important when promoting positive intergroup attitudes amongst adolescents, but positive intergroup attitudes in adulthood can buffer against the often found reduction in intergroup contact with age. These findings 
demonstrate that interventions aimed at reducing intergroup bias and discrimination which exacerbates social inequality should target adolescents rather than adults, and subsequently positive attitudes in adulthood are likely to mean individuals maintain contact with those from disadvantaged groups.

Intergroup contact, however, is not always positive; it can involve negative experiences especially if the conditions for optimal contact outlined above are not meet. The result of negative intergroup contact is often intergroup conflict between individuals from different social groups. Recent developmental research with children and adolescents living in cultures with high conflict and exposure to violent contact between groups was examined by Niwa, Boxer, Dubow, Huesmann, Landau, Shikaki and Gvirsman (in press). The research revealed the negative consequences that such non-optimal contact has for normative beliefs about the outgroup. Niwa and colleagues (in press) investigated longitudinal patterns of aggressive behavior and emotional distress as they co-occur among Palestinian eight to fourteen-year-old children who experienced ethno-political violence over three years. It noted a number of unique profiles for aggressive behavior and emotion distress, in particular a significant one involving high aggression and emotional desensitization, which was strongly associated with support for beliefs shared amongst the ingroup about showing aggression towards the outgroup.

This research shows the corrosive effect that ethnic-political violence and negative contact on intergroup attitudes and relations amongst children and adolescents who develop aggressive and emotionally disturbed profiles. It suggests that ethnic-political violence in an intergroup context can result in support for more violence against the perceived aggressor, such that violence begets violence. Intergroup conflict is likely to only increase further inequity and injustice within societies so what is needed is a close examination of the contextual variables in place that would be necessary to enable intergroup contact to promote positive intergroup attitudes and, therefore, help reduce intergroup conflict and social inequalities.

\section{Future research on intergroup attitudes and prejudice}


A review of the research on intergroup attitudes underscores the importance of identifying developmental mechanisms and contexts for promoting equity and justice. For much of the recent research on the factors that reduce prejudice, the focus has been on the feasibility of changing majority group attitudes to become more inclusive and less biased (Pettigrew \& Tropp, 2005), as well as on how parents from under-represented groups prepare their children for the world of discrimination (Hughes, et al., in press). More recently, developmental science has expanded its focus to include how prejudice can be reduced through understanding both the majority and minority perspectives, and how majority parents might be perpetuating prejudice through avoiding important opportunities to teach about prejudice (Pahlke, Bigler, \& Suizzo, 2012), as well as how all parents may potentially discourage cross-group friendships, dating, and marriage.

The focus on the minority perspective is important because the optimal conditions for those who are the targets of prejudice may be different from those who perpetuate prejudice. In other words, social psychology researchers have argued that cross-group friendships may reduce prejudicial attitudes held by high status majority group members but other experiential factors may be important for those who are the recipients of prejudice such as engaging in collective action to effect change (Dixon, Levine, Reicher, \& Durrheim, 2012). This is an essential aspect of how to enact change. Yet, child and adolescent patterns may be different from adult ones. In a study with low-income African-American and Latino youth, intergroup contact (cross-race friendships) was related to the likelihood that interracial exclusion was viewed as wrong and with an awareness of the wrongfulness of stereotyping (Ruck, Park, Killen, \& Crystal, 2011). Thus, more research is needed regarding when children challenge stereotypic expectations, resist going along with the group when the group is perpetuating outgroup dislike or accepting the status quo, and rectifying social inequalities. To create programs for intervention it is necessary to investigate the ways in which both adults and children contribute 
to negative social relationships, as well as to understand the experiences of the recipients of prejudice and discrimination.

\section{Economic and policy mandates to reduce social inequalities in children's lives}

Economic indicators have shown that the long-term consequences of inequality are quite detrimental in terms of a lack of educational success, family cohesiveness, or secure income obtainment (Duncan, et al., 2015). This area or research has identified the societal and economic factors that contribute to a lack of equitable and just treatment; from this vantage point, policy mandates are necessary to protect children from suffering undue hardships. The evidence from this area of research has provided the basis for changes in policy regarding quality of care in the first 3 years of life, promoting maternal health, and encouraging early pre- $\mathrm{K}$ education, as well as provided evidence of socioeconomic factors, such as poverty, that contribute to long term negative trajectories for children. As an example, anti-poverty programs in the 1990s predicted positive outcomes for low-income minority boys by adolescence, and that moving from a high poverty area to a low one had positive long term effects through to adulthood (Ludwig et al., 2012; Snell et al., 2013). These areas reflect a macro level analysis and one that draws on social policy, behavioral economics, political science, and educational research. Weiland and Yoshikawa et al.'s (2012) research, for example, underscores how ethnic minority children from immigrant families and children in families who are coping with economic challenges experience prejudice, social exclusion, and discrimination.

\section{Future research in developmental science}

In this last section, we review areas of developmental research that could contribute to the science of inequality and disparities by integrating a more explicit consideration of equity and justice themes. We highlight examples of influential topics in developmental science with the goal of providing new ideas for future lines of research, complementing existing findings.

Cognitive neuroscience. Even before President Obama's BRAIN Initiative, developmental scientists have had a keen interest in mapping cognitive and neurological 
processes to socioemotional and behavioral processes. While this area has offered new and innovative insight into the neurological underpinnings of developmental processes, the research would have an even stronger impact on developmental science by including a more explicit focus on concerns of social equity and justice. For example, technological advances have enabled anatomical and functional MRI scans providing insight into developmental neuroscience. Research coupling MRI scan with longitudinal approaches from childhood to adolescence have found white matter to increase linearly with age, with males exhibiting a steeper slope (Giedd et al., 1999). In contrast, gray matter decreased in a non-linear pattern, and patterns of decline differ for different regions of the brain.

One of the key observations of this line of research is that gray matter actually increases during pre-adolescence, signaling a critical developmental period where brain development may be particularly susceptible to environmental influences and cues. Giedd et al. (1999) hypothesize that the increase in gray matter is the brain's way of preparing for environmental cues that will result in selective synaptic trimming. Indeed, recent research has begun to link neurological development to adolescent development, specifically in the area of risk-taking (Steinberg, 2015). Environmental cues, in this case, the presence of peers, has been observed to increase adolescent risk-taking. Scholars have speculated that pubertal development may be at least partially responsible for the increased influence of peers; and in particular, increased affiliation with deviant peers (Ge, Brody, Conger, Simons, \& Murry, 2002). Yet, this research may be masking relevant dipartites in vulnerable groups. For example, recent research suggests a complex association between pubertal development and depression in African American and European-American girls (Keenan, Culbert, Grimm, Hipwell, \& Stepp, 2014). While African American youth begin puberty earlier than their European-American peers, they also report a longer time to completion, essentially spending more time in pubertal development.

Given this disparity, the science of neurological development and its socioemotional and behavioral consequences may be an area that would benefit from a broader consideration of 
social context for equity and justice purposes. For example, known racial disparities in neighborhood and educational opportunities may moderate the effects of peers on risky decision-making. While risky behavior may be a normative component of adolescent development, the social contexts in which adolescents engage in risky behaviors (e.g., urban versus rural environments) likely influences the spectrum of risky behaviors that are available to adolescents. These types of behaviors, in turn, have important implications for developmental outcomes such as psychological and physical health, educational opportunities, academic outcomes, and adult development.

Developmental cognitive neuroscience research has shown the effects on social inequality (as measured by social-economic status) on the neurobehavioral functioning in children, with specific impairment in language and executive functioning by school age (e.g., Noble et al., 2005). Recent research also indicates that the effects of social inequality on brain activity can already be identified in the first months of life, which highlights a potential increase in the risk for subsequent atypical developmental outcomes and the need to focus interventions to challenge the negative consequence on this very early period of infant development (Karmiloff-Smith et al., 2014). This important research could benefit from a further focus on equity and justice, since socio-economic status is often confounded with ethnicity or race with infants and children from ethnic/racial minority status groups, who also during development experience discrimination and prejudice, being overrepresented in low SES groups. Future research should, for example, examine the connection between early social inequality in infancy, later ethnic or racial discrimination in childhood and adolescence and negative psychological and neurological outcomes.

Bullying and victimization. Peer relationships play a fundamental role in children's social development. Friendships provide opportunities for developing positive conflict resolution strategies such as compromising and negotiating (Dunn, 2004), learn how to share resources (Paulus \& Moore, 2014) and serve as a buffer against victimization (Hodges, Boivin, Vitaro, \& 
Bukowski, 1999). Yet, when peer relationships are antagonistic, the negative long-term consequences are severe, and pose obstacles to healthy development. For example, children who display externalizing behaviors such as being highly uninhibited are at risk for aggressive traits and for bullying behavior; in contrast, children who display internalizing behaviors such as being shy, fearful, and wary of others are at risk for extreme social withdrawal and for being victimized (Rubin, Bukowski, \& Parker, 2006).

While much has been learned about the interpersonal dynamics of peer relationships, much less is known about the intergroup dynamics for contributing to cycles of bullying behavior. While interpersonal dynamics reflect the personality traits that contribute to individual differences to explain bully-and-victim relationships, intergroup dynamics reflect the group norms, group identity, and stereotypes that contribute to victimization that stems from prejudicial attitudes. These prejudices feed discrimination which helps sustain social inequality and injustice in both child and adolescence. Whereas personality traits contribute to $10 \%-15 \%$ of the child population that is at risk for becoming bullies and victims, prejudicial attitudes, both explicit and implicit, are often held by a larger segment of the population, becoming normative expectations about individuals based on group membership. Thus, an examination of the factors that contribute to intergroup social exclusion in childhood and adolescence is important for revealing information about the sources of bullying and victimization in childhood that reflect prejudicial attitudes and contribute to social exclusion and social inequalities based on group membership.

Several recent findings have pointed to areas for further study. Inclusive intergroup norms held by peers are related to prosocial behavior towards members of outgroups whereas exclusive intergroup norms are related to more aggressive behavior towards those identifying with the outgroup (Nesdale, 2004). Additional research to investigate the intersection of personality traits and group norms regarding members of ingroups and outgroups would help understand how both processes contribute to bully-victim patterns of behavior. 


\section{Conclusion}

In conclusion, in advocating for a developmental science of equity and justice we make three assertions. First, that equity and justice reflect important areas of developmental science theory and research which have not yet been recognized as central areas of research in the discipline. Second, that existing research across different areas in developmental science on the topics of equity and justice share a common concern for understanding and challenging social inequalities. Finally, that equity and justice research within developmental science can enlighten policies and practices aimed at advancing the experiences of stigmatized groups, reducing prejudice and bias where ever it appears, and designing interventions to put right social inequalities endured by children and adolescents. We described studies from developmental science that support the existence of isolated but robust findings regarding the inequity and inequalities that children experience and the factors that reduce the negative longterm consequences of such experience. As well we identified the attitudes that children hold very early in life which perpetuate exclusion as well as the role played by adults regarding the messages that they communicate in everyday life. Policies and intervention programs are sorely needed to determine how best to intervene and promote a society of equals.

As the guest editors for a current special section of Child Development entitled Equity and Justice in Developmental Science: Discrimination, Social Exclusion, and Intergroup Attitudes, we hope that these articles contribute to our goals for identifying current research on this topic, and moving the field forward. In congruence with Graham's commentary (Graham, in press), we argue that developmental science has a unique opportunity to contribute to the ongoing societal discussions about social inequalities which have been part of the current discourse at the national and international levels. Children's lives are at stake, as well as the health and wellbeing of the current and next generation. 


\section{References}

Aboud, F. E. (1988). Children and prejudice. Oxford, England: Blackwell.

Allport, G. W. (1954). The nature of prejudice. Reading, MA: Addison Wesley.

Anderson, E. (1999). What is the point of equality? Ethics, 109, 287-337.

Andrews, N., Martin, C., Field, R., Cook, R., \& Lee J. (in press). Development of expectancies about own- and other-gender group interactions and their school-related consequences. Child Development.

Appiah, K. A. (2005). The ethics of identity. Princeton: Princeton University Press.

Baron, A. S. (2015). Constraints on the development of implicit intergroup attitudes. Child Development Perspectives. http://doi.org/10.1111/cdep.12105

Baysu, G., Celeste, L., Brown, R., Vershueren, K., \& Phalet, K. (in press). Minority adolescents in ethnically diverse schools: Perceptions of equal treatment buffer threat effects. Child Development.

Benner, A. D., \& Graham, S. (2007). Navigating the transition to multi-ethnic urban high schools: Changing ethnic congruence and adolescents' school-related affect. Journal of Research on Adolescence, 17, 207-220. http://doi.org/10.1111/j.1532-7795.2007.00519.x

Berenson, K. R., Gyurak, A., Ayduk, Ö., Downey, G., Garner, M. J., Mogg, K., .. Pine, D. S. (2009). Rejection sensitivity and disruption of attention by social threat cues. Journal of Research in Personality, 43, 1064-1072. http://doi.org/10.1016/j.jrp.2009.07.007

Bigler, R. S., Brown, C. S., \& Markell, M. (2001). When groups are not created equal: Effects of group status on the formation of intergroup attitudes in children. Child Development, 72, $1151-1162$.

Bigler, R. S., \& Liben, L. S. (1993). A cognitive-developmental approach to racial stereotyping and reconstructive memory in Euro-American children. Child Development, 64, 1507-1518.

Brenick, A., \& Romano, K. (in press). Perceived peer and parent outgroup norms, cultural identity, and adolescents' reasoning about peer intergroup exclusion Child Development. 
Brown, C. S., Bigler, R. S., \& Chu, H. (2010). An experimental study of the correlates and consequences of perceiving oneself to be the target of gender discrimination. Journal of Experimental Child Psychology, 107, 100-117. http://doi.org/10.1016/j.jecp.2010.04.010

Chae, D. H., Nuru-Jeter, A. M., Adler, N. E., Brody, G. H., Lin, J., Blackburn, E. H., \& Epel, E. S. (2014). Discrimination, racial bias, and telomere length in African-American men. American Journal of Preventive Medicine, 46, 103-111. http://doi.org/10.1016/j.amepre.2013.10.020

Chavous, R. M., Rivas-Drake, D., \& Smalls, C. (2008). Gender matters, too: The influences of school racial discrimination and racial identity on academic engagement outcomes among African American adolescents. Developmental Psychology, 44, 637-654.

Dixon, J., Levine, M., Reicher, S., \& Durrheim, K. (2012). Beyond prejudice: Are negative evaluations the problem and is getting us to like one another more the solution? Behavior and Brain Sciences, 35, 411-466. http://doi.org/10.1017/S0140525X11002214

Duncan, G. J., Magnuson, K., \& Votruba-drzal, E. (2012). Boosting family income to promote child development. The Future Of Children, 24, 99-120.

http://doi.org/10.1353/foc.2014.0008

Dunn, J. (2004). Children's friendships: The beginning of intimacy. Oxford: Blackwell Publishing. Durkheim, E. (1893). The division of labour in society. NY: The Free Press.

Eisenberger, N. I. (2006). Identifying the neural correlates underlying social pain: Implications for developmental processes. Human Development, 49, 273-293.

Fisher, C. B., Wallace, S. A., \& Fenton, R. E. (2000). Discrimination distress during adolescence. Journal of Youth \& Adolescence, 29, 679-695.

Fourie, C., Schuppert, F., \& Wallimann-Helmer, I. (2015). The nature and distinctiveness of social equality. In C. Fourie, F. Schuppert, \& I. Wallimann-Helmer (Eds.), Social equality: On what it means to be equals (pp. 1-17). Oxford, U.K.: Oxford University Press.

Frankenberg, E., \& Orfield, G. (2007). Lessons in integration: Realizing the promise of racial diversity in American schools. Charlottesville, VA: University of Virginia Press. 
García Coll, C., Lamberty, G., Jenkins, R., McAdoo, H. P., Crnic, K., Wasik, B. H., \& Vázquez García, H. (1996). An integrative model for the study of developmental competencies in minority children. Child Development, 67, 1891-1914. http://doi.org/10.2307/1131600

Ge, X., Brody, G. H., Conger, R. D., Simons, R. L., \& Murry, V. M. (2002). Contextual amplification of pubertal transition effects on deviant peer affiliation and externalizing behavior among African American children. Developmental Psychology, 38, 42-54. http://doi.org/10.1037/0012-1649.38.1.42

Giedd, J. N., Blumenthal, J., Jeffries, N. O., Castellanos, F. X., Liu, H., Zijdenbos, A., ... Rapoport, J. L. (1999). Brain development during childhood and adolescence: A longitudinal MRI study. Nature Nueroscience, 2, 861-863. http://doi.org/10.1038/13158

Gieling, M., Thijs, J., \& Verkuyten, M. (2010). Tolerance of practices by Muslim actors: An integrative social-developmental perspective. Child Development, 81, 1384-1399.

Graham, S. H. (in press). The role of race/ethnicity in a developmental science of equity and justice. Child Development.

Greene, M. L., Way, N., \& Pahl, K. (2006). Trajectories of perceived adult and peer discrimination among Black, Latino, and Asian American adolescents: Patterns and psychological correlates. Developmental Psychology, 42, 218-238.

Harrell, J. P., Hall, S., \& Taliaferro, J. (2003). Physiological responses to racism and discrimination: An assessment of the evidence. American Journal of Public Health, 93, 243-248. http://doi.org/10.2105/AJPH.93.2.243

Hitti, A., \& Killen, M. (2015). Expectations about ethnic peer group inclusivity: The role of shared interests, group norms, and stereotypes. Child Development, 86, 1522-1537. http://doi.org/10.1111/cdev.12393

Hodges, E. V. E., Boivin, M., Vitaro, F., \& Bukowski, W. M. (1999). The power of friendship: Protection against an escalating cycle of peer victimization. Developmental Psychology, 35, 94-101. 
Horn, S. S. (2007). Leaving LGBT (lesbian, gay, bisexual, and transgender) students behind. In C. Wainryb, J. Smetana, \& E. Turiel (Eds.), Social development, social inequality, and social justice (pp. 131-153). New York: Lawrence Erlbaum Associates.

Horn, S. S., \& Sinno, S. (2014). Gender, sexual orientation, and discrimination based on gender and sexual orientation. In M. Killen \& J. G. Smetana (Eds.), Handbook of moral development (2nd ed., pp. 317-339). New York, NY: Psychology Press.

Hughes, D., Del Toro, J., Harding, J., Way, N. \& Rarick, J. (in press). Trajectories of discrimination across adolescence: Associations with academic, psychological and behavioral outcomes. Child Development.

Juvonen, J., Nishina, A., \& Graham, S. (2006). Ethnic diversity and perceptions of safety in urban middle schools. Psychological Science, 17, 394-401.

Katz, P. A. (1983). Developmental foundations of gender and racial attitudes. In R. L. Leahy (Ed.), The child's construction of social inequality (pp. 41-78). New York: Academic Press.

Keenan, K., Culbert, K. M., Grimm, K. J., Hipwell, A. E., \& Stepp, S. D. (2014). Timing and tempo: Exploring the complex association between pubertal development and depression in African American and European American girls. Journal of Abnormal Psychology, 123, 725-736. doi.org/10.1037/a0038003

Killen, M., Mulvey, K. L., \& Hitti, A. (2013). Social exclusion in childhood: A developmental intergroup perspective. Child Development, 84, 772-790. doi.org/10.1111/cdev.12012

Killen, M., \& Rutland, A. (2011). Children and social exclusion: Morality, prejudice, and group identity. Children and social exclusion: Morality, prejudice, and group identity. New York, NY: Wiley-Blackwell. doi.org/10.1002/9781444396317

Killen, M., Rutland, A., \& Ruck, M. (2011). Promoting equity, tolerance, and justice in childhood. Social Policy Report: Sharing Child and Youth Development Knowledge, 25, 1-33.

Krieger, N. (2012). Methods for the scientific study of discrimination and health: An ecosocial 
approach. American Journal of Public Health, 102, 936-945.

http://doi.org/10.2105/AJPH.2011.300544

Lai, C. K., Marini, M., Lehr, S. A., Cerruti, C., Shin, J.-E. L., Joy-Gaba, J. A., ... Nosek, B. A. (2014). Reducing implicit racial preferences: A comparative investigation of 17 interventions. Journal of Experimental Psychology. General, 143, 1765-85. http://doi.org/10.1037/a0036260

Ludwig, J., Duncan, G. J., Gennetian, L. A., Katz, L. F., Kessler, R. C., Kling, J. R., \& Sanbonmatsu, L. (2012). Neighborhood effects on the long-term well-being of low income adults. Science, 337, 1505-1510. http://doi.org/10.1126/science.1224648

Marks, A. K., Ejesi, K., McCullough, M. B., \& Garcia Coll, C. (2015). Developmental implications of discrimination. In M. E. Lamb \& R. M. Lerner (Eds.), Handbook of child psychology and developmental science (7th ed., pp. 324-365). NY: John Wiley \& Sons, Inc.

Masten, C. L., Eisenberger, N. I., Borofsky, L. A., Pfeifer, J. H., McNealy, K., Mazziotta, J. C., \& Dapretto, M. (2009). Neural correlates of social exclusion during adolescence:

Understanding the distress of peer rejection. Social Cognitive and Affective Neuroscience, 4, 143-157. http://doi.org/10.1093/scan/nsp007

McEwen, B. S. (2012). Brain on stress: How the social environment gets under the skin. PNAS Proceedings of the National Academy of Sciences of the United States of America, 109, $17180-17185$.

Mistry, R. S., Brown, C. S., Chow, K. A., \& Collins, G. S. (2012). Increasing the complexity of young adolescents' beliefs about poverty and inequality: Results of an 8th grade social studies curriculum intervention. Journal of Youth and Adolescence, 41, 704-716. http://doi.org/10.1007/s10964-011-9699-6

Mulvey, K. L., \& Killen, M. (2015). Challenging gender stereotypes: Resistance and exclusion. Child Development, 86, 681-694. http://doi.org/10.1111/cdev.12317

Mulvey, K.L., Palmer, S., \& Abrams, D. (in press). Race-based humor and reer group 
dynamics in adolescence: Bystander intervention and social exclusion. Child Development. Neblett, E. W., \& Carter, S. (2012). The protective role of racial identity and Africentric worldview in the association between racial discrimination and blood pressure. Psychosomatic Medicine, 74, 509-516.

Nesdale, D. (2004). Social identity processes and children's ethnic prejudice. In M. Bennett \& F. Sani (Eds.), The development of the social self (pp. 219-245). New York: Psychology Press.

Newheiser, A.-K., \& Olson, K. R. (2012). White and Black American children's implicit intergroup bias. Journal of Experimental Social Psychology, 48, 264-270. http://doi.org/10.1016/j.jesp.2011.08.011

Niwa, E., Boxer, P., Dubow, E., Huesmann, R.L., Landau, S., Shikaki, K. \& Gvirsman, S. (in press). Growing up amid ethno-political conflict: Aggression and emotional desensitization promote hostility to ethnic out-groups. Child Development.

Nussbaum, M. C. (1999). Sex and social justice. Oxford, England: University of Oxford Press. Page-Gould, E., Mendoza-Denton, R., \& Tropp, L. R. (2008). With a little help from my crossgroup friend: Reducing anxiety in intergroup contexts through cross-group friendship. Journal of Personality and Social Psychology, 95, 1080-1094. http://doi.org/10.1037/00223514.95.5.1080

Pahlke, E. E., Bigler, R. S., \& Suizzo, M. (2012). Relations between colorblind socialization and children's racial bias: Evidence for European-American mothers and their preschool children. Child Development, 83, 1164-1179.

Pascoe, E. A., \& Smart Richman, L. (2009). Perceived discrimination and health: A metaanalytic review. Psychological Bulletin, 135, 531-554. http://doi.org/10.1037/a0016059

Pauker, K., Xu, Y., Williams, A., \& Biddle, A. (in press). Race essentialism and social contextual differences in children's racial stereotyping. Child Development. 
Paulus, M., \& Moore, C. (2014). The development of recipient-dependent sharing behavior and sharing expectations in preschool children. Developmental Psychology, 50, 914-921. http://doi.org/10.1037/a0034169

Pettigrew, T. F., \& Tropp, L. R. (2005). Allport's intergroup contact hypothesis: Its history and influence. In J. F. Dovidio, P. Glick, \& L. Rudman (Eds.), Reflecting on the nature of prejudice: Fifty years after Allport (pp. 262-277). Malden, MA: Blackwell.

Pitula, C., Murray-Close, D., Banny, A. M., \& Crick, N. R. (2015). Prospective associations between peer aggression and victimization: The moderating roles of physiological stress reactivity and gender. Social Development, 24, 621-639. http://doi.org/10.1111/sode.12110

Rawls, J. (1971). A theory of justice. Cambridge, MA: Harvard University Press.

Ridgeway, C. L. (2013). Why Status Matters for Inequality. American Sociological Review, 79, 1-16. http://doi.org/10.1177/0003122413515997

Rivas-Drake, D., Hughes, D., \& Way, N. (2009). A preliminary analysis of associations among ethnic racial socialization, ethnic discrimination, and ethnic identity among urban sixth graders. Journal of Research on Adolescence, 19, 558-584. http://doi.org/10.1111/j.15327795.2009.00607.x

Robbins, J. M., \& Krueger, J. I. (2005). Social projection to ingroups and outgroups: A review and meta-analysis. Personality and Social Psychology Review, 9, 32-47. http://doi.org/10.1207/s15327957pspr0901

Rubin, K. H., Bukowski, W. M., \& Parker, J. G. (2006). Peer interactions, relationships, and groups. In N. Eisenberg, W. Damon, \& R. M. Lerner (Eds.), Handbook of child psychology: Social, emotional, and personality development (6th ed., Vol. 3, pp. 571-645). Hoboken, NJ US: John Wiley \& Sons Inc.

Rutland, A., \& Killen, M. (2015). A developmental science approach to reducing prejudice and social exclusion: Intergroup processes, social-cognitive development, and moral reasoning. 
Social Issues and Policy Review, 9, 121 - 154.

Scheffler, S. (2015). The practice of equality. In C. Fourie, F. Schuppert, \& I. Wallimann-Helmer (Eds.), Social equality: On what it means to be equals (pp. 21-44). Oxford, U.K.: Oxford University Press.

Schmidt, M. F. H., Svetlova, M., Johe, J., \& Tomasello, M. (2016). Children's developing understanding of legitimate reasons for allocating resources unequally. Cognitive Development, 37, 42-52. http://doi.org/10.1016/j.cogdev.2015.11.001

Sen, A. K. (2009). The idea of justice. Harvard University Press.

Snell, E. K., Castells, N., Duncan, G., Gennetian, L., Magnuson, K., \& Morris, P. (2013). Promoting the positive development of boys in high-poverty neighborhoods: Evidence from four anti-poverty experiments. Journal of Research on Adolescence, 23, 357-374. http://doi.org/10.1111/jora.12014

Steele, C. M. (1997). A threat in the air: How stereotypes shape intellectual identity and performance. American Psychologist, 52, 613-629.

Steinberg, L. (2015). How to improve the health of American Adolescents. Perspectives on Psychological Science, 10, 711-715. http://doi.org/10.1177/1745691615598510

Tajfel, H., \& Turner, J. C. (1986). The social identity theory of inter-group behavior. In S. Worchel \& W. Austin (Eds.), Psychology of Intergroup Relations (pp. 7-24). Chicago: Nelson Hall.

Tenenbaum, H. R., \& Ruck, M. D. (2012). British adolescents' and young adults' understanding and reasoning about the religious and non-religious rights of asylum-seeker youth. Child Development, 83, 1102-1115. http://doi.org/10.1111/j.1467-8624.2012.01755.x

Thijs, J., \& Verkuyten, M. (in press). Ethnic attitudes and social projection in the classroom. Child Development.

Tropp, L., O’Brien, T., Gonzalez, R., Valdenegro, D., Migacheva, K., de Texanos Pinto, P., 
Berger, C., \& Cayul, O. (in press). How school norms, peer norms, and discrimination predict inter-ethnic experiences among youth. Child Development.

Van Goethem, A., Van Hoof, A., Orobio de Castro, B., Van Aken, M., \& Hart, D. (2014). The role of reflection in the effects of community service on adolescent development: A metaanalysis. Child Development, 85, 2114-2130. http://doi.org/10.1111/cdev.12274

Verkuyten, M. (2011). Cross-ethnic friendships and parents. Social Policy Report: Sharing Child and Youth Knowledge, 25, 28-29.

Weiland, C., \& Yoshikawa, H. (2012). The effects of large-scale economic change and policies on children's developmental contexts and developmental outcomes. Child Development Perspectives, 6, 342-350. http://doi.org/10.1111/j.1750-8606.2011.00222.x

Wray-Lake, L., Syvertsen, A. K., \& Flanagan, C. A. (2008). Contested citizenship and social exclusion: Adolescent Arab American immigrants' views of the social contract. Applied Developmental Science, 12, 84-92. http://doi.org/10.1080/10888690801997085

Yip, T. (2014). The effects of ethnic/racial discrimination and sleep quality on depressive symptoms and self-esteem trajectories among diverse ddolescents. Journal of Youth and Adolescence, 419-430. http://doi.org/10.1007/s10964-014-0123-x

Yip, T., Douglass, S., \& Sellers, R. M. (2014). Ethnic and racial identity. In F. Leong, L. ComasDiaz, G. Nagayama, V. McLoyd, \& J. Trimble (Eds.), APA Handbook of multicultural psychology (pp. 179-205). Washington, D. C.: APA Press. 